\title{
El dilema de las cláusulas escalonadas en Colombia
}

\author{
Luisa María Brito Nieto*
}

\begin{abstract}
RESUMEN
Las cláusulas escalonadas son cada vez de mayor utilización en la contratación actual, tanto a nivel nacional como internacional, gracias a las facilidades que aportan a la hora de buscar soluciones satisfactorias y eficientes a conflictos de gran envergadura. Sin embargo, la admisibilidad, validez y obligatoriedad de las mismas ha sido controvertida, principalmente por la dificultad a la hora de dilucidar las consecuencias jurídicas que conlleva el no agotamiento de las etapas menos adversariales, previas al arbitraje. La problemática a la luz del ordenamiento jurídico colombiano sube de punto, sobre todo a raíz de la entrada en vigencia de la actual legislación procesal, que consagra una probibición expresa de pactar requisitos de procedibilidad de carácter extralegal. En razón de ello, en el presente escrito se analiza: i) la admisibilidad o no de las cláusulas escalonadas, sus respectivas consecuencias jurídicas y la conveniencia práctica o no de pactarlas en el plano internacional; ii) la probibición expresa de pactar requisitos de procedibilidad extralegales, consagrada en la actual normatividad procesal colombiana y las dificultades que la misma genera; y iii) las repercusiones que conlleva la nulidad de la cláusula escalonada en la validez del pacto arbitral inserto en ella.
\end{abstract}

Cláusulas escalonadas o multinivel - pacto arbitral - validez

\section{The dilemma of the multi-tiered clauses in Colombia}

\begin{abstract}
The multi-tiered clauses are increasingly used in current contracting both at national and international levels due to the facilities they provide in seeking satisfactory and efficient solutions to conflicts of great significance. However, the admissibility, validity and enforceability of such clauses have been controversial, mainly because of the difficulty in elucidating the legal consequences of not going through the less adversarial stages prior to arbitration. The issue in the Colombian legal system entails a greater controversy especially as a result of the entry into force of recent procedural legislation that enshrines an explicit probibition regarding the agreement of procedural requirements not contemplated in the law. Given said circumstances, the present paper analyses: (i) the admissibility or non-eligibility of the multi-tiered clauses, their
\end{abstract}

* Abogada, Universidad Externado de Colombia. Magíster en derecho, Universidad de Valencia, España. Investigadora del Departamento de Derecho Procesal, Universidad Externado de Colombia. Correo electrónico: luisa.brito@uexternado.edu.co

Artículo recibido el 24 de abril de 2018 y aceptado para su publicación en este número el 1 de agosto de 2019 
legal consequences and the practical convenience of having them agreed at international level; ii) the unequivocal probibition contained in Colombian current procedural regulation regarding parties agreeing procedural requirements not contemplated in the law and the difficulties that it causes; and iii) the consequences of the nullity of the multi-tiered clause in the validity of the arbitration agreement inserted in it.

$$
\text { Multi-tiered clauses - arbitration agreement - validity }
$$

\section{Generalidades aCerca de las Cláusulas escalonadas}

$\mathrm{E}$

n el presente acápite se delimitará lo que se considera como cláusula escalonada, su utilidad, los posibles inconvenientes prácticos a la hora de pactarlas y su admisibilidad en el plano internacional.

\section{1. ¿Qué son las cláusulas escalonadas?}

Las cláusulas escalonadas ${ }^{1}$ son requisitos de resolución de conflictos -normalmente insertas en un contrato o con referencia a él- que consagran etapas diferentes y escalonadas para resolver ciertas controversias derivadas del contrato, previendo fases menos adversariales antes de la utilización de mecanismos heterocompositivos.

De manera preliminar, se debe tener presente que las cláusulas multinivel son variables, no estáticas, y su redacción, así como la previsión de cada una de las etapas de resolución de conflictos, dependerá de cada caso concreto. No obstante, todas tienen en común que no es posible seguir las etapas de forma paralela, sino que será necesario agotar previamente un escalón o etapa antes de continuar con la siguiente ${ }^{2}$.

En ese sentido, es muy común en la práctica contractual la consagración de un deber de negociación, por un período determinado, antes de iniciar un arbitraje. En ese sentido, la operancia de la cláusula consiste en que ${ }^{3}$ se tiene un término específico para agotar la etapa prearbitral contemplada en la cláusula de resolución de controversias ${ }^{4}$. En ese orden de ideas, de no existir acuerdo alguno, se continuará sucesivamente con la siguiente fase que prevea la cláusula, hasta llegar, si así esta lo dispone, a la posibilidad de comenzar un arbitraje 5 .

\footnotetext{
${ }^{1}$ Estas cláusulas también se conocen como multinivel, multi tiered clauses o multi step clauses. Adicionalmente se conocieron inicialmente como Scott Avery clauses, gracias a que el caso Scott vs. Avery (1856) fue su primer antecedente (TALAmás, 2015, pp. 41-45).

${ }^{2}$ Cfr. GonZÁlez, 2007, pp. 200-124.

${ }^{3}$ Claro está, teniendo en cuenta las particularidades que la cada cláusula disponga.

${ }^{4}$ Cfr. Entrena et al., 2014, pp. 761-775.

${ }^{5}$ Cfr. Salcedo, 2015, pp. 89-112.
} 
Es decir, las partes, por medio de la cláusula escalonada establecen de manera contractual $^{6}$ fases para la solución del conflicto, las que adoptan variadas formas ${ }^{7}$, pero que generalmente prevén una fase prearbitral y una fase arbitral ${ }^{8}$. Lo anterior, sin perjuicio de que sea posible establecer una cláusula escalonada con fases para la resolución del conflicto de manera distinta al arbitraje, por ejemplo, una cláusula en la que se prevea intentar la negociación, en primera medida, y después, llevar a cabo una mediación, fracasada esta, a las partes no les quedará alternativa distinta -a menos que celebren un pacto arbitral, más específicamente, un compromiso- a la vía judicial. En todo caso, la regla general es que la cláusula escalonada contemple solamente dos fases, con el fin de evitar que se utilice con fines dilatorios?

Normalmente, la fase prearbitral conllevará a un escenario autocompositivo, ya sea por medio de negociación, conciliación, mediación, minitrial, entre otras. Fracasada esta etapa, se pasará a la fase arbitral, que como resultará obvio, consistirá en iniciar un proceso arbitral de acuerdo con lo pactado en la cláusula de resolución de conflictos. Ahora bien, con el fin de evitar que estas cláusulas se utilicen para dilatar y entorpecer la solución de los conflictos y por las razones que se expondrán a lo largo de este escrito, la fase prearbitral debe necesariamente limitarse a un tiempo, de manera que las partes no se estanquen de forma indefinida en la misma ${ }^{10}$.

En consecuencia, la clave del funcionamiento de las cláusulas escalonadas radica en la obligación que adquieren las partes de cumplir con las fases establecidas en ellas, con el fin de intentar llegar a una solución lo más satisfactoria para ambas o de acordar en la mayor cantidad de puntos en conflicto posibles antes de iniciar un proceso arbitral ${ }^{11}$. Asimismo, debe tenerse en cuenta que las particularidades de cada cláusula y el éxito de las mismas para resolver el conflicto dependerá de lo que se ajuste en mejor medida a la relación jurídica existente entre las partes ${ }^{12}$.

\section{Utilidad de la incorporación de cláusulas escalonadas como cláusulas de resolución de conflictos}

Es fundamental tener presente que la utilización de cláusulas escalonadas es cada vez más común en los contratos mercantiles de gran envergadura. Así pues, la inclusión de las mismas para regular de manera más adecuada la relación contractual habida entre las partes, reconoce el dinamismo de las relaciones comerciales y del tráfico jurídico actual ${ }^{13}$.

\footnotetext{
${ }^{6}$ Cfr. Talamás. Op. cit.

${ }^{7}$ Cfr. GonZÁlez. Op. cit., pp. 200-124.

8 Talamás, Op. cit

${ }^{9}$ Cfr. Talamás. Op. cit.

${ }^{10}$ Cfr. Salcedo. Op. cit.

11 Ibid.

12 Cfr. Talamás. Op. cit.

${ }^{13}$ Cfr. Berlinguer, 2013, p. 2.
} 
Toda vez que las cláusulas multinivel prevén una etapa prearbitral, caracterizada por la utilización de Mecanismos Alternativos de Resolución de Conflictos (MASC) con mayor carga autocompositiva, presenta importantes bondades ${ }^{14}$ particularmente en los casos en los que las partes han tenido una relación jurídico-contractual estable y duradera y pretenden mantenerla para beneficio mutuo. Lo anterior, ya que permite: i) intentar dar una solución a la controversia de carácter amistoso que no deteriore su relación comercial ${ }^{15}$, antes de instaurar un litigio; y ii) resolver de manera más expedita e incluso con mayor experticia las disputas que por sus particularidades son de más fácil solución, dejando que solo los conflictos en los que no pueda llegarse a un acuerdo y que implican mayor complejidad lleguen a un procedimiento más largo y adversarial ${ }^{16}$.

Sin embargo, como resulta obvio, se debe tener especial cuidado a la hora de incluir y redactar este tipo de cláusulas en un contrato, ya que es necesario tener clara la intención de llegar a una solución amistosa antes de ir directamente a un litigio, de lo contrario, podrá resultar más bien un obstáculo para las partes que deseen iniciar de manera directa un proceso arbitral. El inconveniente surgiría también en el caso en que a pesar de haberse convenido una cláusula escalonada, al momento de surgir el conflicto una de las partes no desee llegar a una solución amistosa, caso en el que deberá evaluarse si el pacto tiene carácter coercitivo o no, como veremos en acápites ulteriores.

Adicionalmente, la utilización de este tipo de cláusulas conlleva además a que las partes obtengan una solución al conflicto - muy seguramente- en menor tiempo, lo que generará, en la mayoría de los casos, una reducción de los costos de un litigio ${ }^{17}$. Además, se tendrá la garantía de que el conflicto se mantenga confidencial, lo que es supremamente relevante en el caso de controversias y empresas de gran envergadura ${ }^{18}$. Aunado a ello, y si se logra un consenso parcial o total en la fase prearbitral, el conflicto se habrá solucionado de manera menos traumática, logrando un acuerdo satisfactorio y conveniente para ambas partes ${ }^{19}$. Sin embargo, y como ya fue mencionado, la otra cara de la moneda de estas claras ventajas radica en que, si no se redacta de manera restringida en el tiempo, puede utilizarse como maniobra torticera para entorpecer la solución de la controversia ${ }^{20}$.

\footnotetext{
${ }^{14}$ Cfr. Entrena et al. Op. cit.

${ }^{15}$ Cfr. Salcedo. Op. cit.

${ }^{16}$ Cfr. Bernal et al., 2012.
}

${ }^{17}$ De acuerdo con el estudio anual elaborado en el 2017, por Fullbright \& Jaworski LLP, el 55\% de los casos en los que se intentaron implementar medidas preventivas de litigios se utilizaron los MASC.

${ }^{18}$ Cfr. Talamás. Op. cit.

19 Cfr. Entrena et al. Op. cit.

${ }^{20}$ Ibid. 


\section{Dificultad práctica de las cláusulas multinivel}

Ahora bien, pactar cláusulas escalonadas y dotarlas de obligatoriedad, a nuestro juicio, genera un innegable efecto en la práctica: se estaría yendo en total contravía de la esencia de los MASC autocompositivos, es decir, de la voluntad actual.

Como se ha mencionado someramente, los MASC - en mayor medida aquellos que son autocompositivos- buscan brindar figuras menos adversariales a los sujetos inmersos -o que pueden estarlo- en un conflicto para la búsqueda de soluciones más amistosas, sin la necesidad de deferir la solución de un conflicto a un tercero que, muchas veces, no encontrará una solución que resulte más o menos satisfactoria para ambas partes. Además, el sometimiento a cualquier MASC autocompositivo tiene un requisito elemental: la voluntad de las partes de someterse a él, sin estar obligados los contratantes a recurrir al mismo ${ }^{21}$.

En el caso de las cláusulas escalonadas, si una de las partes al momento de enfrentarse a un conflicto no desea agotar la fase prearbitral, si bien no puede pasarse por alto que tuvo una voluntad previa de llevar a cabo una fase prearbitral, no tiene una voluntad actual de hacerlo, lo que iría en contra del principio más elemental para el éxito de un MASC autocompositivo, que es la voluntad actual de las partes. La consecuencia obvia de obligar a la parte contractual que no tiene voluntad actual de someterse a la fase prearbitral sería el muy probable fracaso de la misma.

Como es sabido, los MASC de manera forzosa no surten buenos resultados. Este es el caso de Colombia, donde es requisito de procedibilidad previo a interponer la demanda ante la jurisdicción ordinaria ${ }^{22}$ el agotamiento de la conciliación prejudicial ${ }^{23}$, la que no tiene actualmente mucho éxito ${ }^{24}$. Esta es la misma razón por la que en ordenamientos jurídicos extranjeros se ha eliminado el requisito de procedibilidad establecido en la ley relativo a agotar una mediación o conciliación previa a interponer una demanda ${ }^{25}$.

No obstante lo anterior, debe precisarse desde ya que el solo hecho que genere dificultades el forzar a las partes que no poseen voluntad actual a agotar la etapa previa al arbitraje -toda vez que podría afectar los futuros resultados satisfactorios de la misma- no es óbice para que el ordenamiento jurídico les reste total validez y coercibilidad, como veremos que sucede en el ordenamiento jurídico colombiano.

${ }^{21}$ Cfr. León, Op. cit.

${ }^{22}$ Este requisito no aplica al arbitraje, toda vez que se entendió que sería un contrasentido imponer requisitos de procedibilidad a un mecanismo que ya es alternativo de solución de controversias.

23 Artículo 90 del CGP.

${ }^{24}$ Cfr. Bernal. Op. cit.

${ }^{25}$ Por ejemplo, por medio de la Ley 5/2012, de mediación en asuntos civiles y mercantiles, se eliminó la mediación obligatoria en España como requisito de procedibilidad. 


\section{Admisibilidad de las cláusulas escalonadas en el contexto internacional}

Como podrá dilucidarse de lo ya expuesto, las cláusulas escalonadas gozan cada vez de mayor aceptación. Al respecto, por ejemplo, de conformidad con el Reglamento de Arbitraje y Mediación de la Cámara de Comercio Internacional (CCI), se recomienda a las partes a someterse a arbitraje o a mediación, o a ambas, para esto será necesario la incorporación de cláusulas adecuadas de resolución de controversias ${ }^{26}$. Para ello expresamente dispone el mencionado reglamento que lo más adecuado es incluir cláusulas multinivel que proporcionen una combinación de ambas técnicas, dentro de las que se podrá incluir el recurso a un peritaje o a los dispute boards ${ }^{27}$, para lo que el mismo Reglamento prevé cláusulas modelo ${ }^{28}$. Aunado a lo anterior, dentro de las cláusulas modelo se consagra la posibilidad de pactarse realizar la mediación y el arbitraje de manera paralela ${ }^{29}$, es decir, no deberá esperarse a concluir con la mediación para poder instaurar el arbitraje, así como la opción de pactar una cláusula escalonada ${ }^{30}$ de arbitraje y mediación ante la CCI.

Adicionalmente, el artículo 13 de la Ley Modelo de la CNUDMI sobre Conciliación Comercial Internacional $^{31}$ (en adelante LM) dispone que cuando las partes acuerden intentar una conciliación y se haya pactado de manera expresa un plazo para ello, mientras no se cumpla dicha etapa, ninguna de las partes podrá iniciar válidamente ningún proceso judicial o arbitral con relación a la misma controversia.

También se destaca que la Ley 5/2012, de 5 de marzo, de mediación en asuntos civiles y mercantiles en España, señala en su artículo 6.2. la validez del pacto escrito que exprese el compromiso de intentar una mediación de manera previa a la vía judicial o a cualquier otro MASC. No obstante, el numeral 6.3. dispone que no se estará obligado a mantenerse en el procedimiento de mediación ni tampoco a concluir en acuerdo, de manera que debe agotarse de manera obligatoria - si así se pactó- antes de iniciar un arbitraje, pero una vez instaurado el procedimiento de mediación, ninguna de las partes se encontrará obligada a permanecer en él ${ }^{32}$.

No obstante lo anterior, uno de los temas más discutidos actualmente acerca de las cláusulas escalonadas es su validez y consecuente obligatoriedad, que derivan, incluso, de su naturaleza híbrida ${ }^{33}$. En todo caso, debe afirmarse que las decisiones al respecto no han sido del todo unánimes y dependerán, incluso, del país del que se trate y de la ley del arbitraje aplicable al caso concreto ${ }^{34}$.

\footnotetext{
${ }^{26}$ Página 3 del Reglamento.

27 Página 79 del Reglamento.

28 Páginas 98 a 102 del Reglamento.

${ }^{29}$ Cláusula C. Página 99 del Reglamento.

${ }^{30}$ Cláusula D. Página 100 del Reglamento.

${ }^{31}$ El artículo 1.3. de la LM regula también supuestos de mediación.

32 Cfr. Entrena et al. Op. cit.

33 Ibid.

${ }^{34}$ Cfr. Cremades, 2016, pp. 57-70.
} 
En lo que respecta a Estados Unidos, en el caso Kemiron Atlantic vs. Aguakem International ${ }^{35}$, la Corte de Apelaciones del undécimo circuito afirmó que, debido a que existía una cláusula escalonada con una clara obligación de realizar una mediación durante un tiempo determinado, era necesario concluir que la misma era válida y se trataba de una condición previa de intentar la mediación para así poder instaurar un arbitraje. En ese sentido, se ha indicado que cuando la cláusula escalonada se encuentre claramente redactada ${ }^{36}$, existe la obligación de las partes de agotar los escalones pactados, en virtud de que ellas mismas han acordado iniciar un arbitraje como una última opción ${ }^{37}$.

Por su parte, en Inglaterra ha habido mayor reticencia respecto de estas cláusulas y se ha considerado que negociar de buena fe no es una obligación de carácter válido y menos ejecutable, a menos que se delimite con absoluta claridad y de manera previa el proceso a seguir, la forma de seleccionar al tercero mediador y su forma de pago ${ }^{38}$.

A su vez, en Francia se ha dado validez a este tipo de cláusulas y, como consecuencia de ello, se han inadmitido demandas argumentando que las causales de inadmisión no son taxativas y que, sin inconveniente alguno, las partes podrían pactar condiciones que impidieran la admisión de la demanda ${ }^{39}$. En ese sentido, se aclaró que la existencia de una cláusula escalonada y el no seguimiento de la fase prearbitral no era causal de incompetencia del tribunal arbitral ni tampoco de anulación del laudo ${ }^{40}$. Adicionalmente, se ha considerado que en los casos en los que se pruebe que una de las partes ha realizado todos los esfuerzos posibles para intentar resolver la controversia por medio de lo dispuesto en la fase prearbitral, así se fracase en ello, podrá iniciarse válidamente un arbitraje ${ }^{41}$.

De cualquier forma, las consecuencias derivadas del incumplimiento de la cláusula escalonada dependerán de la naturaleza jurídica de la cláusula misma. En ese sentido, si se considera de naturaleza contractual, el no cumplimiento de lo dispuesto en ella conllevaría a un incumplimiento del contrato, lo que generaría daños y una correlativa indemnización de perjuicios ${ }^{42}$. No obstante, a nuestro juicio la misma debe considerarse de naturaleza híbrida, al tener un origen contractual y desplegar efectos en la esfera

${ }^{35}$ United States Court of Appeals, eleventh circuit, Kemiron Atlantic vs. Aguakem International 8.05.2002, $\mathrm{N}^{\circ}$ 01-16400.

${ }^{36}$ En el caso caso United States District Court, Cumberland and York Distribution vs. Coors Brewing Co. 07.02.2002, Nº 01-244-P-H, se consideró que la cláusula era ambigua toda vez que no se había delimitado temporalmente la mediación.

${ }^{37}$ En ese sentido se falló en el caso Court of Chancery of Delaware, Dave Greytak vs. Mazda Motors of America 28.01.1992, No 11997; y el caso United States Court of Appeals, Devalk Lincoln Mercury Inc. vs. Ford Motor Co 23.02.1987, No 86-1638.

${ }^{38}$ House of Lords, Channel Tunnel Group vs. Balfour Beatty Construction Ltd. 17.02.1993, Adj.L.R. 01/21; England and Wales High Court, Cable \& Wireless vs. IBM, [2002] EWHC 2059; House of Lords, Walford vs. Miles, [1992] 2 AC 128.

${ }^{39}$ No obstante, la mencionada causal de inadmisión es saneable Corte de Casación francesa, 2ème civ., 16.12.2010, RTD civ, 2011, p. 170; Corte de Casación, com., 03.05. 2011, RDC, 2011, p. 884.

${ }^{40}$ Cfr. BARBet, 2016.

${ }^{41}$ Caso No 8462, CCI, 2003 y Caso Nº 9977, CCI, 2003.

42 Cfr. Talamás. Op. cit. 
procesal, por lo que sería más acertado, a la hora de resolver acerca de las consecuencias de su incumplimiento, inclinarse por la inadmisión de la demanda -pudiendo sanearse- por la falta del agotamiento de un requisito de procedibilidad pactado de manera previa por las partes.

Adicionalmente, puede verse también cómo la redacción de la cláusula ha influido en la valoración de los tribunales a la hora de analizar su obligatoriedad, ya que, como se evidenció, su validez y obligatoriedad dependerán de la interpretación que a esta se le dé ${ }^{43}$. Lo anterior, toda vez que, de encontrarse una cláusula de carácter ambiguo, será dudosa también la voluntad de las partes y en qué condiciones deberán llevarse a cabo los escalones pactados para la solución de la controversia. En ese sentido, la eficacia de la cláusula escalonada se vería mermada y afectada por la falta de determinación y claridad ${ }^{44}$, deviniendo la misma en patológica ${ }^{45}$. En estos casos, la cláusula podría resultar inaplicable, y generaría las consecuencias previstas en el artículo II. $3 .{ }^{46}$ de la Convención sobre el Reconocimiento y Ejecución de Sentencias y Arbitrajes Extranjeras, Nueva York, 1958 (en adelante, CNY). Sin embargo, es elemental tener presente que cada vez más son los pronunciamientos en favor de la aplicación del principio favor arbitri en el caso de cláusulas patológicas, lo que no excluiría el caso en el que una cláusula escalonada lo fuera ${ }^{47}$.

Para evitar lo anterior, las directrices de la International Bar Association (en adelante IBA) para Cláusulas Arbitrales ${ }^{48}$, aprobadas por la Resolución del Consejo de la IBA del 7 de octubre de 2010, pretenden ayudar a lograr cláusulas arbitrales más efectivas. En ese sentido, prevé ${ }^{49}$ directrices para la redacción de cláusulas escalonadas de resolución de controversias, a causa de su común incorporación en contratos internacionales y los retos específicos que presentan en su redacción. Para ello recomienda la observancia de las siguientes reglas:

- Señalamiento de un período corto de tiempo específico para la negociación o mediación, luego de ello, cualquiera de las partes podrá instaurar un arbitraje, indicando el hecho que desencadenará el conteo del mismo. Esta regla tiene como finalidad evitar que la cláusula escalonada se utilice con fines dilatorios. En este punto deberá tenerse en cuenta que no en todos los casos el inicio de la negociación o de la mediación generará la suspensión de términos de prescripción.

\footnotetext{
${ }^{43}$ Cfr. Entrena et al. Op. cit.

${ }^{44}$ Tribunal Supremo de Justicia Español. 20.06.2002. RJ 2002/5256, se le restó validez a la cláusula por considerarse ambigua.

${ }^{45}$ Cfr. Artuch, 1997, pp. 176 y ss.; Cfr. Derains, 2005, pp. 192 y ss.; Cfr. Entrena et al. Op. cit.; Cfr. Fernández, 2016, pp. 697-725; Cfr. León. Op. cit.; Cfr. Verdera y Esplugues. 2004, pp. 389 y 390.

46 "El tribunal de uno de los Estados Contratantes al que se someta un litigio en el que las partes hayan concluido un acuerdo en el sentido del presente artículo, remitirá a las partes al arbitraje, a instancia de una de ellas, a menos que compruebe que dicho acuerdo es nulo, ineficaz o inaplicable".

47 Cfr. Fernández. Op. cit., pp. 697-725.

48 Disponibles en: www.ibanet.org.

49 Directriz IV.
} 
- Evitar consagrar en la cláusula al arbitraje como facultativo y no como obligatorio $^{50}$. De esta manera se impedirá que la cláusula devengue en patológica por ser ambigua la intención de someter las controversias a arbitraje que no puedan resolverse por el o los escalones anteriores. Acerca de este punto en particular, haremos algunas precisiones más adelante.

- Definir claramente las controversias que quieren someterse a negociación o mediación y arbitraje en términos iguales. De lo contrario, si se determinan para la etapa prearbitral y para la arbitral no, habrá supuestos en los que ciertas controversias podrán someterse directamente a arbitraje.

De cualquier modo, para admitir la validez de estas cláusulas y su consecuente obligatoriedad debe prestarse especial atención en los siguientes aspectos: i) redacción clara y precisa de la cláusula en el sentido de indicar que el agotamiento de la fase prearbitral es un requisito para continuar con la fase arbitral; y ii) prever detalladamente las condiciones de cada una de las fases, de manera que pueda valorarse que cada fase ha sido agotada ${ }^{51}$.

Ahora bien, ¿cuál es la consecuencia de admitirse la validez y obligatoriedad de la cláusula escalonada? En el caso en el que se haya presentado la demanda o la solicitud de arbitraje sin agotar los escalones previos, en aras de garantizar la economía procesal, a nuestro criterio, sería conveniente inadmitir la demanda y que se ordene a las partes al agotamiento de la o las fases prearbitrales ${ }^{52}$. En ese sentido, de acuerdo con el principio kompetenz-kompetenz ${ }^{53}$ el competente para dirimir esta cuestión es el tribunal arbitral. No obstante, si se da inicio a un proceso judicial y ambas partes guarden silencio, se considerará una renuncia ${ }^{54}$ a lo dispuesto en la cláusula escalonada en su totalidad, tanto de la fase prearbitral como arbitral.

En suma, y como se señaló en este acápite del escrito, el tratamiento que se le dé a este tipo de cláusulas en cuanto a su validez y obligatoriedad va a depender ${ }^{55}$ de lo que disponga la lex arbitri ${ }^{56}$.

\footnotetext{
${ }^{50}$ Normalmente consagradas como que las partes "podrán” (may o shall) someterse a arbitraje.

51 Cfr. Entrena et al. Op. cit.

52 Ibid.

53 Cfr. CoOK, 2014.

${ }^{54}$ Cfr. Entrena et al. Op. cit.

55 Cfr. Bernal. Op. cit.

${ }^{56} \mathrm{La}$ lex arbitri hace referencia al conjunto de normas que rigen el arbitraje, que corresponde a la ley de la sede del mismo. Cfr. Redfern et al., 2006, pp. 155-156.
} 


\section{Consecuencias JuRídicas de la prohibición de paCtar Cláusulas} ESCALONADAS A LA LUZ DE LA NORMATIVIDAD COLOMBIANA

Si bien en el panorama internacional hemos visto que, de un modo u otro, se ha aceptado la validez y en ciertos casos la obligatoriedad de las cláusulas multinivel, a la luz del ordenamiento jurídico colombiano la consecuencia de pactar estas cláusulas no es la misma. Por ello, en el presente epígrafe se estudiará la prohibición expresa que realiza el artículo 13 de la Ley N 1564 de 2012, por medio de esta se expide el Código General del Proceso (CGP) de pactar requisitos de procedibilidad extralegales, así como las consecuencias jurídicas que genera y las repercusiones que su nulidad pueda conllevar respecto de la validez del pacto arbitral.

\section{La probibición consagrada en el CGP}

El artículo 13 del CGP consagra la prohibición de pactar cláusulas que establezcan el agotamiento de requisitos de procedibilidad para acceder a la administración de justicia.

Ahora bien, al disponerse constitucionalmente que los árbitros están investidos transitoriamente de la función pública de administrar justicia -lo que es clara muestra de la inclinación hacia una teoría jurisdiccional del arbitraje ${ }^{57}$ - y ya que la Ley $\mathrm{N}^{0} 1563$ de 2012, Estatuto de Arbitraje Nacional e Internacional, guardó silencio al respecto, el arbitraje doméstico se encuentra cobijado con esta prohibición ${ }^{58}$. Sin embargo, consideramos que lo mismo no sucedería ante un arbitraje internacional con sede en Colombia ${ }^{59}$, en virtud de que rige, en mayor medida, lo pactado por las partes (pacta sunt servanda). Adicionalmente, esta es una norma meramente de carácter local, por lo que no haría parte del orden público internacional de la sede.

En primera medida es menester señalar que la legislación predecesora del CGP ${ }^{60}$, si bien consagraba el carácter de orden público de las normas procesales, no contenía la mencionada prohibición, por lo que no cortaba de plano la posibilidad de pactar el agotamiento de requisitos previos para instaurar una demanda sin violar la normatividad procesal. Sin embargo, la coercibilidad de estas cláusulas no era clara.

Existieron pronunciamientos del Consejo de Estado previos a la entrada en vigencia del $\mathrm{CGP}^{61}$ y solo en materia de arbitraje nacional, afirmándose que el acceso a la administración de justicia no podía quedarse condicionado al agotamiento de requisitos previos en virtud de cláusulas escalonadas, por tanto estas no eran válidas ni de

${ }^{57}$ Cfr. Bernal. Op. cit.

58 Consejo de Estado, 10.06. 2009, Rad. 11001-03-26-000-2009-00001-00 (36252).

59 No obstante, a la fecha no se cuentan con pronunciamientos acerca de la materia en Colombia.

${ }^{60}$ Artículo 6 del Decreto 1400 del 6 de agosto de 1970, por el que se expidió el Código de Procedimiento Civil, actualmente derogado por el CGP.

${ }^{61}$ La norma que nos atañe entró en vigencia el 1 de enero de 2016, de conformidad con el Consejo Superior de la Judicatura, Acuerdo 11.10.2015, N PSAA15-10392. 
obligatorio cumplimiento ${ }^{62}$. Sin embargo, el Tribunal Superior del Distrito Judicial de Bogotá le dio completa validez a estas cláusulas, en virtud de la autonomía privada de las partes, por lo que, si no se agotaban los escalones previos, el tribunal arbitral carecería de jurisdicción y el laudo sería nulo ${ }^{63}$. Por su parte, la Corte Constitucional en sede de tutela, en aras de preservar la voluntad de las partes al pactar una cláusula escalonada, previó que su obligatoriedad no constituía una violación al efectivo acceso a la administración de justicia ${ }^{64}$.

Ahora bien, el Proyecto del CGP preparado por la Comisión Redactora tampoco contemplaba esta prohibición ${ }^{65}$. Incluso, durante las sesiones llevadas a cabo por la Comisión Redactora no se puso sobre la mesa la problemática que nos atañe ${ }^{66}$. En ese entendido, el Proyecto de Código General del Proceso se sometió a los respectivos debates en el Congreso de la República ${ }^{67}$ y en el pliego de modificaciones contenido en el Informe para Segundo Debate en el Senado ${ }^{68}$ fue incluido el inciso que consagra la prohibición expresa de acordar el agotamiento de requisitos de procedibilidad distintos a los contemplados en la ley, así como se encuentra contemplado actualmente en el CGP ${ }^{69}$.

La incorporación del mencionado inciso fue realizada única y exclusivamente para prohibir la inclusión de cláusulas escalonadas como cláusulas de resolución de controversias, ya que se consideró que las mismas contrariaban el carácter imperativo de las normas procesales y tenían como fin cercenar el derecho al libre acceso a la administración de justicia con la imposición de requisitos de procedibilidad distintos a los previstos por la ley ${ }^{70}$.

${ }^{62}$ Consejo de Estado, 29.11. 2012, Rad. 39.332; Consejo de Estado, 04.12.2006, Rad. 32.871.

${ }^{63}$ Tribunal Superior de Bogotá, 26.02.2008, Rad. 2006 - 00887; Corte Suprema de Justicia, 28.03.2008, Exp. T-11001-02-03-000-2008-00384-00.

${ }^{64}$ Corte Constitucional, T-058-09.

${ }^{65}$ Acta N ${ }^{\circ} 68$ de la Comisión Redactora del Proyecto de Código General del Proceso.

${ }^{66}$ Acta N 72 de la Comisión Redactora del Proyecto de Código General del Proceso.

${ }^{67}$ En los mencionados debates se mantuvo el texto de manera intacta. Cámara de Representantes. Gaceta Año XX-N 116 del 29 de marzo de 2011. Cámara de Representantes. Gaceta Año XX-No 250 de 2011. Cámara de Representantes. Gaceta Año XX-Nº 745 de 2011. Cámara de Representantes. Gaceta Año XX-N 822 de 2011.

${ }^{68}$ Senado de la República. Gaceta Año XXI-Nº 261 de 2012.

${ }^{69}$ Senado de la República. Gaceta Año XXI-No 316 del 6 de junio de 2012.

${ }^{70}$ Se mencionó en el Pliego de Modificaciones: "Se incluye un inciso $2^{\circ}$ en el que se determinan de manera expresa algunas de las estipulaciones que contrarían el carácter imperativo de las normas procesales, conocidas como 'cláusulas escalonadas'. Tales pactos tienen como propósito o como efecto impedir o restringir el derecho al libre acceso a la administración de justicia a través de la imposición de trámites extralegales previos, en ocasiones sumamente costosos en términos de tiempo y dinero. La disposición adicionada dispone una ineficacia de pleno derecho para este tipo de acuerdos, que como consecuencia de ello no vinculan a las partes del contrato, ni pueden ser invocados por ellas para alegar el incumplimiento del contrato en caso de que se acuda directamente a la jurisdicción sin haber cumplido con el trámite allí dispuesto. En el inciso $3^{\circ}$ se precisa además que las estipulaciones a las que allí se hace referencia son aquellas que han sido pactadas por las partes, para evitar equívocos de interpretación con otras fuentes de derecho". Senado de la República. Gaceta Año XXI-No 261 de 2012. 
Actualmente, la norma que rige la materia es el artículo 13 del CGP que dispone -en lo que nos atañe- de manera clara y expresa lo siguiente:

- Los acuerdos relativos al agotamiento de requisitos de procedibilidad extralegales no se consideran de obligatoria observancia. En ese sentido, el artículo 13 del CGP le resta total eficacia a este tipo de cláusulas, que, en todo caso, no obligarán de ningún modo a las partes. Tan es así, que el último inciso del mencionado artículo dispone que este tipo de estipulaciones se tendrán por no escritas.

- En consecuencia clara de la regla anterior, instaurar una demanda sin agotarse los requisitos pactados no se podrá considerar incumplimiento de lo acordado, por lo que, de acuerdo con la normatividad, no podrá condenarse a la indemnización de perjuicios por incumplimiento de la cláusula escalonada.

- Presentar una demanda sin agotarse los requisitos pactados no será un obstáculo para que el juez o el árbitro tramiten la demanda ${ }^{71}$.

En suma, resulta más que evidente que del tenor literal de la norma se elimina la posibilidad de pactar cláusulas multinivel, lo que, sin duda alguna, no se encuentra en consonancia con las tendencias del comercio y, más aun, de los contratos internaciona$\operatorname{les}^{72}$. De cualquier modo, es innegable que en la práctica no es extraño encontrarnos ante cláusulas de este tipo ${ }^{73}$, toda vez que las partes, al momento de la celebración del contrato, tienen la intención de prever una fase previa al arbitraje con el fin de llegar a un acuerdo acerca de la mayor parte de los puntos en controversia, antes de llegar a un arbitraje. Esta preocupación ha generado, incluso, que se haya presentado un Proyecto de Ley con el fin de modificar el artículo 13 del CGP, con el propósito de garantizar la efectividad de las cláusulas escalonadas, en el sentido de limitar la nulidad de estas cláusulas solamente al caso en el que el agotamiento de requisitos de procedibilidad para acceder a cualquier operador de justicia tenga como finalidad obstruir el acceso a la administración de justicia, es decir, cuando sea abusiva ${ }^{74}$.

En conclusión, la prohibición expresa que se encuentra en el artículo 13 del CGP -que como vimos se incorporó con la única intención de prohibir las cláusulas escalonadas- le resta validez a las mismas si estas llegan a pactarse como requisito previo y como condición sine qua non a la vía arbitral o judicial ${ }^{75}$. No obstante, esto no impediría que

${ }^{71}$ En aplicación de este precepto, se ha dispuesto de manera jurisprudencial que, en efecto, dichas cláusulas no son obligatorias y no impiden el acceso directo al arbitraje o a los jueces estatales. Ver: Consejo de Estado, 18.04.2017, Rad. 50001-23-33-000-2015-00667 01 (58461).

72 Cfr. Salcedo. Op. cit.

${ }^{73}$ Ejemplo de ello es la cláusula escalonada incorporada en el contrato de concesión $\mathrm{N}^{\circ} 053$ celebrado entre la Unidad Ejecutiva Especial de Servicios Públicos -UESP- y el Consorcio Aseo Capital S.A. E.S.P. (Consejo de Estado, 31.10.2016, Rad. 11001-03-26-000-2016-00099-00 (57.422)), y en el contrato UELSED-04-131/00/03 de diseño y ejecución de obras entre la Secretaría de Educación de Bogotá y la Unión Temporal (cláusula 24) (Corte Constitucional, Auto 097-2013).

${ }^{74}$ Proyecto de ley 96/2017, para la modificación del artículo 13 del Código General del Proceso.

${ }^{75}$ Cfr. Robledo, 2013, pp. 333. 
las partes prevean de manera anticipada la manera en la que desean resolver sus conflictos en una fase previa al arbitraje si en el momento de surgir el conflicto ambas continúan con el deseo de resolverlo amistosamente, aunque sea de manera parcial ${ }^{76}$. Esto no quiere decir que la mencionada fase sea obligatoria y constituya un requisito de procedibilidad, pero sí configuraría una ayuda a las partes que, a la hora de verse inmersas en un conflicto, quieren hacer uso de mecanismos autocompositivos de solución de conflictos.

\section{Dificultades que genera la probibición del artículo 13 del CGP}

Si bien del tenor literal del artículo en comento, la prohibición de pactar cláusulas escalonadas de carácter obligatorio es clara, dicha disposición normativa resulta radicalmente garantista ${ }^{77}$ al no tener en cuenta dos aspectos fundamentales en la contratación privada: la autonomía privada ${ }^{78}$ y la teoría del venire contra factum proprium non valet.

a) Respecto de la autonomía privada

La autonomía privada consiste en la facultad que reconoce el ordenamiento jurídico a los sujetos de disponer de sus intereses con efecto vinculante, respetando el orden público, las buenas costumbres y los derechos fundamentales. En ese sentido, la autonomía privada conlleva a que las partes puedan válidamente: i) celebrar contratos o abstenerse de hacerlo, creando en el primer caso vínculos obligacionales; y ii) determinar el contenido de las obligaciones que se contraen, teniendo en cuenta los límites mencionados ${ }^{79}$.

Ahora bien, la Ley 57 de 1887, por el que se expide el Código Civil colombiano (CC), consagra este principio en sus artículos 16 y 1602, en el sentido de preceptuar que no podrán derogarse las leyes que involucren el orden público y las buenas costumbres por convenios entre particulares y de consagrar que el contrato es ley para las partes. En ese orden de ideas, si bien la autonomía privada no es un derecho absoluto, es un derecho íntimamente ligado con la dignidad de la persona, derivado de la imposibilidad del Estado de prever todas las necesidades de los administrados ${ }^{80}$.

En ese sentido, debe tenerse en cuenta también que la libre configuración legislativa en materia procesal también tiene límites ${ }^{81}$. Si bien el legislador está llamado a preservar los principios constitucionales, esto debe ser cumpliendo con principios de proporcionalidad y razonabilidad frente al fin para el que fueron concebidas ${ }^{82}$. No

\footnotetext{
${ }^{76}$ Consejo de Estado, 18.04.2017, Rad. 50001-23-33-000-2015-0066701 (58461).

77 Por lo que el Proyecto de Ley 96 de 2017 nos resulta afortunado.

78 Postura similar tiene MayorCA, 2013, pp. 8 y ss.

${ }^{79}$ Corte Constitucional, C-934, M.P. Nilson Pinilla.

80 Corte Constitucional, C-341/2003. Ver también Corte Constitucional, T-338/1993; Corte Constitucional, C-660/1996; Corte Constitucional, C-738/2002.

${ }^{81}$ Corte Constitucional, C-227/2009.

${ }^{82}$ Corte Constitucional, C-203/2011.
} 
entendemos por qué considerar, en todos los casos y bajo cualquier supuesto, que las cláusulas escalonadas vulneran el libre acceso a la administración de justicia.

De esta manera, a nuestro parecer se estaría hilando demasiado delgado al considerar que un límite válido a la autonomía privada es catalogar de nulas las cláusulas multinivel en todos los casos y bajo cualquier supuesto, con el pretexto de que estas vulneran el libre acceso a la administración de justicia. No se entiende cómo en materia arbitral se le da una importancia suprema a la voluntad de las partes, incluso en aspectos relacionados con el procedimiento -por ejemplo, previéndose la posibilidad de que en arbitraje internacional se pueda renunciar al recurso extraordinario de anulación ${ }^{83}-$, sin considerarse que esto cercene el libre acceso a la administración de justicia ni el debido proceso.

En este punto, olvida el legislador que, a menos que nos encontremos ante circunstancias particulares de una cláusula abusiva, como puede concluirse también de cualquier cláusula arbitral $^{84}$, son las mismas partes las que regulan de manera previa la forma en la que resolverán sus conflictos futuros, en aras de preservar su relación contractual y comercial y de depurar a menos puntos en controversia el objeto del futuro litigio, de ser posible.

\section{b) Respecto de la doctrina del venire contra factum proprium non valet}

Partiendo de la prohibición consagrada en el artículo en comento ¿qué pasaría si las partes incluyen una cláusula escalonada en un conflicto y una de ellas se rehúsa a cumplirla? En virtud del artículo 13 del CGP la respuesta es obvia, esta devendría en nula y se podría iniciar directamente la fase arbitral o judicial. No obstante, también se estaría fomentando ir en contra de los actos propios y vulnerando la confianza legítima ${ }^{85}$.

La máxima venire contra factum proprium non valet hace referencia a la prohibición de ir en contra de sus actos propios. En ese sentido, ninguna persona puede, válidamente, ir en contra de sus actos como fundamento de su derecho de contradicción ${ }^{86}$, en virtud de la relevancia jurídica que se les da a sus actos ${ }^{87}$. En ese orden de ideas, en virtud del principio de buena fe se prohíbe ir en contra de los propios actos, toda vez que las conductas realizadas deben respetarse por las partes contratantes ${ }^{88}$.

De conformidad con esta teoría, no sería válido ni admisible que un individuo ejercite un derecho de forma claramente incompatible con su conducta precedente ${ }^{89}$ ¿no

83 Artículo 107 de la Ley No 1563 de 2012.

${ }^{84}$ Por ejemplo, en ciertos casos en los que una de las partes es un consumidor. Artículos 42 y siguientes de la Ley N 1480 de 2010, por medio de este se expide el Estatuto de Protección al Consumidor.

${ }^{85} \mathrm{Al}$ respecto se pronuncia Cfr. SAlcedo. Op. cit.

${ }^{86}$ Esta deriva del principio de buena fe, consagrado en el artículo 83 de la Constitución Política.

Consejo de Estado, 18.02.2010, Rad. 85001-23-31-000-1997-00403-01 (15596).

${ }^{87}$ Cfr. Bernal et al. , 2012.

${ }^{88}$ Corte Constitucional, T-923/2010.

${ }^{89}$ Ibid. 
sucedería esto en el supuesto que nos planteamos? La respuesta es afirmativa, las partes deberían observar un comportamiento coherente en cualquier fase del contrato, y no aprovecharse de su comportamiento contradictorio 90 . Ahora, ¿no estaría vulnerándose también el principio de confianza legítima, derivado de la buena fe? Creemos que sí, ya que que las partes no pueden súbitamente alterar las reglas que regían su relación jurídica, debiéndose mantener una coherencia en sus actuaciones ${ }^{91}$.

\section{3. ¿La invalidez de la cláusula escalonada viciaría de algún modo el pacto arbitral en Colombia?}

Vistas las consecuencias jurídicas que el CGP les asigna a las cláusulas multinivel, es menester ahora analizar si la invalidez de la cláusula escalonada implicaría, necesariamente y bajo qué supuestos, la nulidad del pacto arbitral. En las siguientes líneas se expondrán las razones por las que puede predicarse la validez del acuerdo de arbitraje así se declare nula la cláusula escalonada. Para ello se tratarán los principios rectores del pacto arbitral, así como la interpretación del artículo 13 del CGP.

a) Principios rectores del pacto arbitral

Con el fin de sostener la validez del pacto arbitral a pesar de la invalidez de la cláusula escalonada, se hará referencia a la separabilidad y la autonomía de la voluntad predicables del pacto, para finalmente realizar las respectivas conclusiones.

- Separabilidad del pacto arbitral

Con la expedición de la Ley N 1563 de 2012 -y en consonancia con lo dispuesto en el artículo 16.1. de la LM-, los artículos 5 y 79 expresamente ${ }^{92}$ señalan que las causas de inexistencia, ineficacia o invalidez del contrato en el que se encuentra inserta una cláusula compromisoria generarían la inexistencia, ineficacia o invalidez del acuerdo de arbitraje.

En ese orden de ideas, no puede predicarse una accesoriedad de la cláusula compromisoria en sentido estricto respecto del contrato en el que esta se inserta, lo que es consecuencia misma de su naturaleza híbrida ${ }^{93}$. Como resulta obvio de lo dicho, las causas de invalidez, inexistencia e ineficacia del pacto arbitral son independientes de

\footnotetext{
${ }^{90}$ Cfr. Bernal, 2010, pp. 253-269.

91 Corte Constitucional, T-1094/2005.

92 Jurisprudencialmente, ya se había predicado la separabilidad del pacto arbitral: Corte Constitucional, C-249/1999; Corte Constitucional, C-035/2008.

93 Este principio comenzó a aparecer en la práctica arbitral internacional con el fallo United States Court of Appeals, Robert Lawrence Company, Inc., Plaintiffappellee, v. Devonshire Fabrics, Inc. 28.10.1959, 271 F.2d 402 (2d Cir. 1959).
} 
las del contrato en las que se encuentra incorporado ${ }^{94}$. Lo anterior permite que pueda pretenderse la nulidad, inexistencia o invalidez del contrato en un proceso arbitral sin afectar la competencia de los árbitros 95 .

Como se puede deducir, el principio de separabilidad es la causa de la verdadera eficacia práctica del arbitraje, ya que es el único modo de que este opere como un mecanismo alternativo de solución de controversias que no dependa de la controversia misma, es decir, del contrato ${ }^{96}$. De esta manera, el tribunal arbitral puede decidir acerca de la validez y eficacia del contrato que contiene una cláusula compromisoria sin despojarse de su propia competencia ${ }^{97}$.

\section{- Autonomía de la voluntad}

El artículo 116 de la Constitución Política permite que las partes acuerden deferir la solución de sus controversias a la decisión de árbitros investidos de la función de administrar justicia. No obstante, un asunto litigioso no es sometido a arbitraje sino por la voluntad de las partes plasmada en un pacto arbitral ${ }^{98}$. De otro modo, no podría iniciarse un proceso arbitral válidamente. En efecto, es gracias a ese acuerdo de voluntades que las partes someten ciertas disputas a la decisión de los árbitros ${ }^{99}$.

Así las cosas, la autonomía de la voluntad, plasmada en un acuerdo de arbitraje, es el pilar del arbitraje ${ }^{100}$. De esta manera, solo mediante el consentimiento de deferir una controversia a la decisión de los árbitros el proceso arbitral puede existir, de lo contrario, la controversia solamente podría ser dirimida acudiendo a un proceso judicial ${ }^{101}$. En consecuencia, y como se podrá anticipar, el consentimiento es un requisito de validez del contrato de arbitraje $\mathrm{e}^{102}$.

Ahora bien, el artículo 3 de la Ley No 1563 de 2012 no dispone de manera expresa que las partes deberán expresar su voluntad en el acuerdo de arbitraje ${ }^{103}$, este requisito se sobreentiende al consagrar que este es un negocio jurídico, el que necesariamente se

${ }^{94}$ Cfr. Chillón y Merino, 1991, pp. 1382 y 1383.

95 Supreme Court of the United States, National Iranian Oil Co v. Crescent Petroleum Co International Ltd \& Anor 9.11.1987, No 87-459.

${ }^{96}$ Cfr. Artuch, 1997 , pp. 108 y ss.

97 Cfr. Virgós, 2006, pp. 316 y ss.

${ }^{98}$ Es necesario tener presente que, si bien la voluntad es un pilar fundamental para que el arbitraje pueda llevarse a cabo, también debe tenerse en cuenta que el mismo encuentra su fundamento también, por lo menos en Colombia y varios países latinoamericanos, en el reconocimiento que se realiza del mismo en la Constitución o en la ley, inclinándonos más por una teoría jurisdiccional del arbitraje. Al respecto, ver BenetTi, 2009, pp. 59 y ss.

99 Corte Constitucional, C-163/1999; Corte Constitucional, SU-174/2007; Corte Constitucional, C-330/2000.

100 Cfr. Suescún, 2010, pp. 4-23.

101 Cfr. Verdera, 2009. Op. cit., pp. 17-19.

102 Cfr. Álvarez, 1996, pp. 144 y ss.; Cfr. Armenta, 2017, p. 537.

${ }^{103}$ Como sí lo hace, por ejemplo, el artículo 9.1. de la Ley 60/2003, de arbitraje español. 
caracteriza por el acuerdo de voluntades. Lo mismo establece el artículo 69 del mismo estatuto normativo en su sección relativa al arbitraje internacional ${ }^{104}$. Aunado a ello, en sentido similar indica el artículo II.1. de la CNY y el artículo 1 de la Convención Interamericana sobre Arbitraje Comercial Internacional, Panamá, 1975, al consagrar la exigencia de la voluntad de las partes para la validez del acuerdo.

\section{- Validez del pacto arbitral a pesar de la nulidad de la cláusula multinivel}

En ese sentido y vistos estos dos principios rectores del acuerdo de arbitraje, debe responderse la pregunta de si, en los casos en los que se declare nula la fase prearbitral, afectaría en algo el consentimiento de someter las controversias a arbitraje, toda vez que las partes celebraron una cláusula de resolución de conflictos en su integridad.

Al respecto, la Corte Constitucional ha declarado la inexistencia de este tipo de convenios $^{105}$ al no existir una clara e inequívoca decisión de someter ciertas controversias a arbitraje al estar la voluntad de las partes condicionada al agotamiento de negociaciones previas, por lo que se consideró que faltaba uno de los elementos esenciales requeridos para la celebración de un pacto arbitral y, por tanto, no existía habilitación a los árbitros.

No obstante, a nuestro parecer, en virtud de la separabilidad del pacto arbitral del contrato en el que se encuentra inmerso - lo que podría predicarse también de la cláusula escalonada - y de la autonomía de las partes consagrada en la fase arbitral prevista, no existiría inconveniente en predicar la validez del contrato de arbitraje. Ahora bien, distinto sería que la cláusula escalonada en sí resulte patológica y no sea posible dilucidar la voluntad de las partes de solucionar sus controversias mediante arbitraje.

b) El artículo 13 del CGP solamente sanciona el agotamiento de requisitos previos al arbitraje

De un análisis literal del artículo 13 del CGP, podría concluirse que, al declararse la nulidad de la cláusula escalonada, sería nula consigo la fase arbitral -es decir, el pacto arbitral-consagrada en la misma. Adicionalmente, a lo anterior podría sumársele que el artículo 1535 del CC consagra como nulas las obligaciones sometidas a condiciones meramente potestativas, es decir, aquellas cuyo acaecimiento dependa, única y exclusivamente, de la voluntad de quien se obliga. En ese sentido, si se considera la fase prearbitral como una condición para poder instaurar el arbitraje, se consideraría como nula la obligación en su totalidad.

Sin embargo, a nuestro criterio, la anterior no es la interpretación correcta, toda vez que va en contra del espíritu y finalidad que la norma pretende cumplir. De conformidad con el artículo 11 del CGP, la ley procesal debe interpretarse teniendo en

${ }^{104}$ En los dos artículos mencionados salta a la vista la importancia de la voluntad real de las partes, al reconocerse el pacto arbitral tácito y por referencia.

105 Corte Constitucional, auto 097/2013. 
cuenta que el objetivo de los procedimientos es la efectividad de los derechos reconocidos por la ley sustancial. De manera adicional, el artículo 27 del CC preceptúa que podrá recurrirse a la intención o espíritu de la norma, manifestados en la misma o en su historia fidedigna.

Como quedó bastante claro en el epígrafe anterior, la única finalidad de la prohibición consagrada en el artículo 13 del CGP era evitar la incorporación contractual del agotamiento de requisitos de procedibilidad extraprocesales, toda vez que se consideró que lo anterior viola y entorpece el libre acceso a la administración de justicia. En ese entendido, lo que la norma castiga no es el pacto arbitral en sí mismo considerado, sino el agotamiento de los requisitos previos a la fase arbitral, por lo que lo que estaría viciado de nulidad sería solamente la fase prearbitral de la cláusula escalonada, dejando intacta la fase arbitral, pudiendo las partes instaurar una demanda arbitral válidamente con fundamento en este pacto.

\section{CONCLUSIONES}

Se esbozan las siguientes conclusiones de lo analizado a lo largo de este trabajo:

1. La tendencia en el ámbito internacional ha sido la de aceptar la validez de las cláusulas escalonadas, siempre y cuando estas se encuentren correctamente definidas en cuanto al límite de tiempo y condiciones específicas bajo las cuales se llevará a cabo la fase prearbitral. No obstante lo anterior, las consecuencias jurídicas derivadas del incumplimiento de las etapas previstas en la cláusula varían dependiendo de la ley aplicable al arbitraje. Ahora bien, y pese a las claras ventajas prácticas que las cláusulas multinivel aportan a la hora de que las partes se enfrenten a un conflicto de gran envergadura, la obligatoriedad de las mismas en el caso en el que una de las partes se rehúse a su cumplimiento, afecta en la práctica el éxito de la misma, en virtud de la carencia de voluntad actual. En todo caso, esto no es óbice para que se les reste validez vía legal.

2. La prohibición expresa de pactar requisitos de procedibilidad extralegales, consagrada en el artículo 13 del CGP tuvo como única finalidad evitar y castigar de nulas las cláusulas multinivel. En ese sentido, y dada la tendencia hacia una teoría jurisdiccional del arbitraje nacional en Colombia, la nulidad de estas cláusulas será predicable en el arbitraje doméstico, más no en el internacional con sede en Colombia, donde prima el pacta sunt servanda. Sin embargo, esta tajante prohibición resulta excesivamente garantista, ya que no en todos los casos las cláusulas multinivel generan limitaciones al libre acceso a la administración de justicia. Aunado a ello, la invalidez de estas cláusulas -bajo cualquier supuesto- vulnera el principio de autonomía privada y la doctrina del venire contra factum proprium non valet.

3. Si bien el artículo 13 del CGP es claro en castigar de nulas las cláusulas escalonadas, la nulidad de las mismas no afectaría la validez del pacto arbitral inserto en 
ellas, en virtud de los principios se separabilidad y autonomía de la voluntad de las partes que rigen el pacto arbitral. Adicionalmente, ya que la tan mencionada prohibición tiene como finalidad castigar únicamente los requisitos de procedibilidad extralegales, no el acuerdo de deferir ciertas controversias a arbitraje.

\section{BiBLIOGRAFÍA}

Álvarez, Pedro, 1996: La anulación del laudo arbitral: el proceso arbitral y su impugnación, Granada: Comares.

Armenta, Teresa, 2017: Lecciones de Derecho Procesal Civil. Proceso de Declaración, Proceso de Ejecución y Procesos Especiales. Procedimiento Concursal, Arbitraje y Mediación, Madrid: Marcial Pons.

ARTUCH, Elena, 1997: El convenio Arbitral en el Arbitraje Comercial Internacional. Madrid: Eurolex. BARBET, Jérôme, 2016: "La clause de conciliation obligatoire préalable est sans incidence sur la compétence de l'arbitre ; la fraude procédurale suppose un grief, note sous Paris”. Disponible en Base de Datos Wolters Kluwer: http://basesbiblioteca.uexternado.edu.co:2108/document/ kli-ka-ra-2016-4-016?q=\%22Poir\%C3\%A9\%20c.\%20Tripier\%22.

Benetti, Julio, 2009: El arbitraje en el derecho colombiano, Bogotá: Cámara de Comercio de Bogotá. Berlinguer, Aldo, 2013: "Hacia un modelo europeo de mediación", Aranzadi doctrinal, № 5. Bernal, Rafael et al., 2012: "Las Cláusulas Escalonadas o Multinivel: Su Aproximación en Colombia”, Revista de Arbitraje Comercial y de Inversiones, vol. 5.

Chillón, José y Merino, José, 1991: Tratado de Arbitraje Privado Interno e Internacional, Madrid, Thomson Civitas.

Cook, Ashley, 2014: "Kompetenz-kompetenz: varying approaches and a proposal for a limited form of negative kompetenz-kompetenz". Disponible en Base de Datos Westlaw International: https://1.next.westlaw.com/Document/Ibd2a05c096cc11e498db8b09b4f043e0/View/FullText. html?originationContext $=$ typeAhead\&transition Type $=$ Default \&contextData $=($ sc. Default $)$

Cremades, Anne, 2016: “¿Qué sanción en caso de incumplimiento de una cláusula escalonada de resolución de controversias?”, Spain Arbitration Review, No 16.

Derains, Yves, 2005: "Cláusulas escalonadas patológicas y combinadas", en Eduardo Silva y Fabricio Mantilla (editores), El contrato de arbitraje, Bogotá, Legis, pp. 191-202.

Entrena, Antonio et al., 2014: "Las cláusulas escalonadas de resolución de conflictos: reflexiones sobre su aplicación práctica", en Xavier Abel Lluch (editor), Las medidas preventivas de conflictos jurídicos en contextos económicos inestables, Barcelona, pp. 761-775.

FERnÁNDEZ, José, 2016: "El convenio arbitral: entre la estabilidad y el desatino", en Eduardo Picand (editor), Estudios de arbitraje, Santiago de Chile, Editorial Jurídica de Chile, pp. 697-725.

GonzÁlez DE Cossio, Francisco, 2007: "La naturaleza jurídica del arbitraje: Un ejercicio de balanceo químico", Lima arbitration, $\mathrm{N}^{\circ} 2$.

León, Amaro, 2013: "El convenio arbitral 1". Disponible en vLex International (serial online), disponible en: EBSCOhost, basesbiblioteca.uexternado.edu.co:2048/login?url=http:// search.ebscohost.com/login. aspx? direct $=$ true $\& \mathrm{db}=$ edsvlx \&AN $=$ vlex. $452287817 \&$ lang $=e$ s\&site $=$ eds-live

Mayorca, Carlos, 2013: "Clases de arbitraje en la nueva ley de arbitraje", en Estatuto Arbitral Colombiano. Bogotá, Legis.

Robledo, Pablo, 2013: "El Estatuto de Arbitraje y el Código General del Proceso”, en Estatuto Arbitral Colombiano. Bogotá, Legis.

Redfern, Alan et al., 2006: Teoría y práctica del arbitraje comercial internacional, Navarra, Aranzadi. 
SALCEDO, Cristhian, 2015: "Hacia una protección merecida: La eficacia de las cláusulas escalonadas en el marco de un pacto arbitral en Colombia", Universitas Estudiantes, № 12: 89-112.

Suescún, Felipe, 2010: "Orden público internacional: excepción a la limitación que imponen los actos administrativos a la competencia de los tribunales de arbitramento", Revista de Derecho Privado, $\mathrm{N}^{\circ} 44$.

TALAmÁs, Ernesto, 2015: "Las cláusulas escalonadas en el arbitraje”, El mundo del abogado, volumen 41.

Verdera, Rafael, 2009: El convenio arbitral, España: Aranzadi.

Verdera, Rafael y Esplugues, Carlos, 2004: "Del convenio arbitral y sus efectos", en Silvia Barona (editora), Comentarios a la Ley de Arbitraje (Ley 60/2013, de 23 de diciembre), Madrid, Thomson Civitas, pp. 315-444.

Virgós, Miguel, 2016: "El convenio arbitral en el arbitraje internacional", Actualidad Jurídica, núm. 14.

\section{Normas jurídicas citadas}

Decreto 1400/1970, por el que se expidió el Código de Procedimiento Civil colombiano, publicado el 6 de agosto de 1970.

Convención sobre el Reconocimiento y la Ejecución de las Sentencias Arbitrajes Extranjeras, adoptada el 10 de junio de 1958. Ratificada por Colombia el 25 de septiembre de 1979.

LEY Modelo de la CNUDMI sobre Arbitraje Comercial Internacional, adoptada el 11 de diciembre de 1985 .

LEY N 57 de 1887, por medio de la cual se expide el Código Civil colombiano, publicada el 20 de abril de 1887.

LEY N ${ }^{\circ}$ 60/2003, de arbitraje español, publicada el 23 de diciembre de 2003.

LEY $\mathrm{N}^{\circ} 1480 / 2010$, por medio de la cual se expide el Estatuto de Protección al Consumidor, publicada el 12 de octubre de 2010.

LEY $\mathrm{N}^{\circ}$ 5/2012, de mediación en asuntos civiles y mercantiles en España, publicada con fecha 6 de julio de 2012 .

LEY N N $^{\circ}$ 1563/2012, por la que se expidió el Estatuto de Arbitraje Nacional e Internacional colombiano, publicada el 12 de julio de 2012.

Ley No $1564 / 2012$, por medio de la cual se expide el Código General del Proceso colombiano, publicada el 12 de julio de 2012.

Proyecto de ley 96/2017, para la modificación del artículo 13 del Código General del Proceso.

\section{Actas de Comisión Redactora y Gacetas del Congreso de la República de Colombia:}

ACta N ${ }^{\circ} 68$ de la Comisión Redactora del Proyecto de Código General del Proceso. Sesión del 18 de mayo de 2005.

Aста N 72 de la Comisión Redactora del Proyecto de Código General del Proceso. Sesión de 20 de julio de 2005.

CÁmara de Representantes. Gaceta Año XX-No 116 del 29 de marzo de 2011.

CÁmara de Representantes. Gaceta Año XX-Nº 250 del 11 de mayo de 2011.

CÁmara de Representantes. Gaceta Año XX-No 745 del 4 de octubre de 2011.

CÁmara de Representantes. Gaceta Año XX-Nº 822 del 3 de noviembre de 2011.

SEnAdo de la República. Gaceta Año XXI-No 261 del 23 de mayo de 2012.

Senado de la República. Gaceta Año XXI-No 316 del 6 de junio de 2012. 
Senado de la República. Gaceta Año XXI-Nº 261 del 23 de mayo de 2012.

Jurisprudencia citada

\section{Colombia:}

Corte Constitucional, sentencia de 24 de agosto de 1993, T-338/1993.

Corte Constitucional, sentencia de 28 de noviembre de 1996, C-660/1996.

Corte Constitucional, sentencia de 17 de marzo de 1999, C-163/1999.

Corte Constitucional, sentencia de 21 de abril de 1999, C-249/1999.

Corte Constitucional, sentencia de 22 de marzo de 2000, C-330/2000.

Corte Constitucional, sentencia de 11 de septiembre de 2002, C-738/2002.

Corte Constitucional, sentencia de 3 de mayo de 2003, C-341/2003.

Corte Constitucional, sentencia de 27 de octubre de 2005, T-1094/2005.

Consejo de Estado, Sección Tercera, sentencia del 4 de diciembre de 2006, Rad. 32.871.

Corte Constitucional, sentencia de 14 de marzo de 2007, SU-174/2007.

Corte Constitucional, sentencia del 23 de enero de 2008, C-035/2008.

Tribunal Superior de Bogotá, sentencia del 26 de febrero de 2008, Rad. 2006 - 00887.

Corte Suprema de Justicia, Sala de Casación Civil, sentencia del 28 de marzo de 2008, Exp. No T-11001-02-03-000-2008-00384-00.

Corte Constitucional, sentencia de 2 de febrero de 2009, T-058/09.

Corte Constitucional, sentencia de 30 de marzo de 2009, C-227/2009.

Consejo de Estado, Sección Tercera, sentencia de 10 de junio de 2009, Rad. 11001-03-26-0002009-00001-00 (36252).

Consejo de Estado, Sección Tercera, sentencia de 18 de febrero de 2010, Rad. 85001-23-31000-1997-00403-01 (15596).

Corte Constitucional, sentencia de 17 de noviembre de 2010, T-923/2010.

Corte Constitucional, sentencia de 24 de marzo de 2011, C-203/2011.

Consejo de Estado, Sección Tercera, sentencia del 29 de noviembre de 2012, Rad. 39.332.

Corte Constitucional, auto de 16 de mayo de 2013, 097/2013.

Corte Constitucional, sentencia de 11 de diciembre de 2013, C-934/2013.

Consejo Superior de la Judicatura, Sala Administrativa, Acuerdo de 1 de octubre de 2015, $\mathrm{N}^{\circ}$ PSAA15-10392.

Consejo de Estado, Sección Tercera, sentencia de 31 de octubre de 2016, Rad. 11001-03-26000-2016-00099-00 (57.422).

Consejo de Estado, Sección Tercera, sentencia de 18 de abril de 2017, Rad. 50001-23-33-0002015-0066701 (58461).

\section{España:}

Tribunal Supremo de Justicia Español, sentencia de 20 de junio de 2002, RJ 2002,5256.

\section{Francia:}

Corte de Casación Francesa, Poiré c. Tripier, Revue, sentencia de 14 de febrero de 2003.

Corte de Apelación de París, Société Nihon Plast co. c. Société Takata-Petri, sentencia de 4 de marzo de 2004.

CORTE de Casación Francesa, sentencia de fecha 12 de diciembre de 2004. 
Corte de Casación Francesa, sentencia de fecha 16 de diciembre de 2010.

\section{Estados Unidos:}

United States Court of Appeals, Robert Lawrence Company, Inc., Plaintiffappellee, v. Devonshire Fabrics, Inc. 28 de octubre de 1959, 271 F.2d 402 (2d Cir. 1959).

United States Court of Appeals, Devalk Lincoln Mercury Inc. vs. Ford Motor Co de fecha 23 de febrero de 1987, $\mathrm{N}^{\circ} 86-1638$.

Supreme Court of the United States, National Iranian Oil Co v. Crescent Petroleum Co International Ltd \& Anor 9 de noviembre de 1987, No 87-459.

Court of Chancery of Delaware, Dave Greytak vs. Mazda Motors of America de fecha de 28 de enero de 1992, $\mathrm{N}^{\circ} 11997$.

United States District Court, Cumberland and York Distribution vs. Coors Brewing Co. de fecha de 7 de febrero de 2002, No 01-244-P-H.

United States Court of Appeals, Kemiron Atlantic vs. Aguakem International de fecha 8 de mayo de 2002, $\mathrm{N}^{\circ}$ 01-16400.

\section{Inglaterra:}

HousE of Lords, Walford vs. Miles, [1992] 2 AC 128.

House of Lords, Channel Tunnel Group vs. Balfour Beatty Construction Ltd., 17 de febrero de 1993, Adj.L.R. 01/21.

ENGLAND and Wales High Court, Cable \& Wireless vs. IBM, [2002] EWHC 2059.

\section{Laudos Arbitrales:}

Caso No 8462 de la Cámara de Comercio Internacional, disponible en: http://library.iccwbo. org $/ \mathrm{dr}$-searchresult.htm?AUTH $=\&$ Timeframe $=\& \mathrm{txtSearchText}=8462 \& \mathrm{rdSb}=$ FullText \&so rt $2=\& \operatorname{chkPubAll}=$ on $\&$ chkPub1 $=$ Bulletin $\&$ chkPub2 $=$ Supplements $\&$ chkPub3 $=$ Dossiers \&c hkPub4 $=$ Other + Publications\&chkPub5 $=$ Rules\&chkSecAll $=\&$ chkSubsec $1=$ Procedural $+\mathrm{D}$ ecisions\&chkSubsec $2=$ Country + Answers\&chkSubsec $3=$ Awards\&chkSubsec $4=$ Articles\&ch kSubsec $5=$ Commission + Reports $\&$ chkSubsec $6=$ Statistical + Reports \&dtFrom $=09 \% 2 \mathrm{~F} 01 \%$ 2F1998\&dtTo $=10 \% 2 \mathrm{~F} 31 \% 2 \mathrm{~F} 2018$

Caso No 9977 de la Cámara de Comercio Internacional, disponible en: http://library.iccwbo.org/ dr-searchresult.htm? AUTH $=\&$ Timeframe $=\& \operatorname{txtSearchText}=9977 \& \mathrm{rdSb}=$ Full Text $\&$ sort $2=$ $\&$ chkSubsec $3=$ Awards \&dtFrom $=09 \% 2$ F01\%2F1998 $\&$ dtTo $=10 \% 2$ F31\%2F 2018

\section{Otros:}

Directrices de la IBA para la Redacción de Cláusulas de Arbitraje Internacional, 7 de octubre de 2010, International Bar Association, Reino Unido.

Reglamento de Arbitraje y Mediación, diciembre de 2017, Cámara de Comercio Internacional, París.

FuLLBRIGHT \& Jaworski LLP, estudio anual 2017. Disponible en: http://www.nortonrosefulbright. com/files/20171025-2017-litigation-trends-annual-survey-pdf-157870.pdf. 